\title{
FLOW PATTERN IN A HORIZONTAL PRIMARY SEPARATOR WITH A PERFORATED BAFFLE
}

(Date received:18.4.08/Date approved:19.2.11)

\author{
Chen Gooi Mee ${ }^{1}$ and Mohamad Iskandr Mohamad Nor ${ }^{2}$ \\ ${ }^{\prime}$ Faculty of Engineering and Technology, Multimedia University, 75450 Bukit Beruang, Melaka. \\ ${ }^{2}$ Department of Chemical Engineering, University of Malaya, 50603 Lembah Pantai, Kuala Lumpur. \\ E-mail: ${ }^{1}$ gimchen@mmu.edu.my
}

\begin{abstract}
It is important in any gravity separator to provide uniform flow conditions between the inlet and the outlets. In this study, two-dimensional Computational Fluid Dynamics (CFD) modelling was used to reveal the problems of a conventional primary gravity separator at the bulk liquid flow zone particularly. Internal device in the form of simple perforated baffle was incorporated to the separator and its effect on improving the uniformity of flow was investigated. A CFD commercial package, ANSYS was used as the simulation tool. The modelling effort concentrated on the inlet and momentum breaker zone and the bulk liquid flow zone. The problem was first simulated in its simplest form, leaving out baffle in order to understand its underlying transport phenomena. The observed results were then discussed and interpreted according to the law of physics. After the fundamental model was successfully developed, it facilitated the optimisation of hole spacing and diameter of a baffle on a separator's performance. Derived Standard Deviation (SD) for the horizontal velocity along the locations at specific position was used as an indicator to the uniformity of flow and the relative severity of recirculation.
\end{abstract}

Keywords: $C F D$, Horizontal Primary Separator, Perforated Baffle, Recirculation

\subsection{INTRODUCTION}

Initial bulk separation of wellhead fluids produced from the petroleum reservoirs is usually achieved in a series of huge pressurised horizontal gravity separators. A horizontal separator is smaller than the vertical or spherical separator of the same capacity, hence it is more economical in terms of cost [1]. The schematic diagram of a horizontal separator is shown in Figure 1. As the liquid phase of oil and water mixture is allowed to settle, a layer of relatively clean free water will appear at the bottom after a period of retention time ranging from 100 seconds to

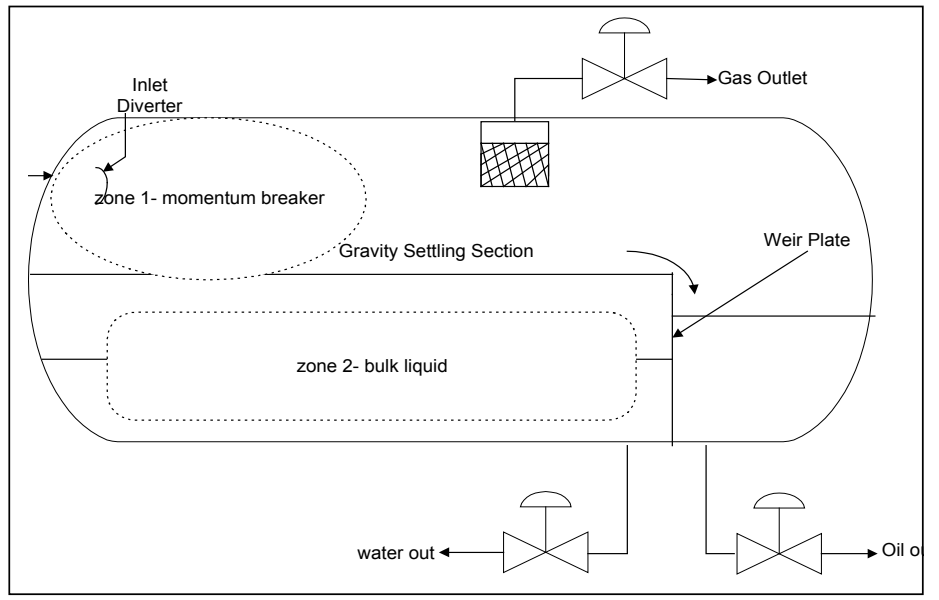

Figure 1: Schematic diagram of horizontal
200 seconds [2]. The water fraction obtained from gravity settling would then be separated through the underflow while the remaining oil layer was removed after the weir plate. Nevertheless, water and oil separation efficiency has been adversely affected by the poor flow pattern in a separator. A substantial zone of recirculating flow in the vessel has contributed to its voluminous size. Typical full size separators are large. Therefore, an important factor in separator design is to minimise the extent of recirculating flow in order to achieve near plug flow across the cross sectional area. CFD modelling had been done in this work to model different aspects of primary separators with the purpose of achieving uniform conditions between the inlets and outlets in any separators.

\subsection{Primary Separator}

Taylor et al. [3] reported that, for steady flow of air through wire gauze, maximum suppression of non-uniformity in longitudinal velocity was achieved with a free area of 45 to $50 \%$, independent of wire diameter. In suppressing turbulent fluctuations, there was no optimum free area but there was a monotonic reduction in the level of fluctuations as free area was reduced. Perforated plate flow conditioners designed to improve flow distribution upstream of an orifice plate flow meter typically had 50 to $60 \%$ free area but a non-uniform distribution of holes of several sizes was employed [4]. 
Hansen et al. [5] developed computer code to analyse the effects of an inlet momentum breaker and a baffle plate on fluid flow behaviour in the separator and carried out supporting experiments. Simulation results for the model incorporating $4 \%$ free area baffle plate was found to be in fair to good agreement with the experimental results. Rashad [6] conducted a study to develop a two dimensional model using a number of different methods with the ultimate objective of distributing the flow in oil/ water separators. The methods simulated included: impingement plates, reverse inlets and porous plates. The preliminary investigation of these methods demonstrated the inadequacy of the use of simple impingement plates and reverse inlets while highlighting the potential of porous plates. Rashad et al. [7] furthered his work using CFD package to develop a single-phase two-dimensional model of a small-scale rectangular separator. The model was used to simulate the effect of porous plates on flow distribution in the separator. Velocity profiles from the experimental and computational models were compared and a good match was found. CFD model was then extended to a three dimensional model. However, modelling was not done on cylindrical vessels nor a perforated baffle. Glynn et al. [8] applied CFD commercial package to study the flow patterns in portable water reservoirs. Poor flow pattern in reservoir with significant regions of recirculatory flow adversely affected the water quality. The effects of various reservoir design parameters i.e. possible insertion of baffle were investigated. Two out of three cases gave simulation results, which were in good accord with field data after a number of simplifications being adopted when constructing the CFD models. Glynn et al. [9] remarked that the convergence attainment was not at all easy for the reservoir CFD modelling although the geometry was simple. The difficulty in convergence was likely due to very low velocity in much of the flow domain.

Wilkinson et al. [10] investigated the feasibility of modelling the flow of the two liquid phases in a separator by CFD simulation and experimental work. The flow field of liquid in two-dimensional and three-dimensional models of horizontal primary oil/ water separators had been studied experimentally using Laser Doppler Anemometry (LDA) and Phase Doppler Anemometry (PDA) measurement techniques. A CFD simulation had also been applied to these configurations to assess its suitability for further modelling work. It was concluded that CFD simulation may be used to investigate design developments of the small two-dimensional separator but it was not suitable for use in the larger three-dimensional separator. Further work was required to establish the cause of this limitation. Wilkinson et al. [11] did a preliminary study using a rudimentary model separator with no internal fittings to verify correspondence between CFD and experimental results. However, as a precursor to experiments involving internal baffles, the results were not encouraging. Wilkinson et al. [12] conducted a program of LDA measurements in two-dimensional and three-dimensional model separators at different scales to identify simple internal fittings that would improve the flow pattern along the length of a separator. Two-dimensional CFD model was modified to study the effect of various baffles on flow distribution across the cross section. Two-dimensional CFD modelling results were found a good simulation of the flow in the two-dimensional experimental model. The three-dimensional separator was not modelled by
CFD. Wilkinson et al. [13] compared the experimental data obtained in a larger three-dimensional cylindrical model with baffles using flows of water only and of a $20 \%$ by volume oil in water mixture respectively with the two dimensional CFD model. A restricted investigation of the flow of oil/water mixtures suggested that results obtained for a single-phase flow could give a useful guide to behaviour to be expected in the 2D-flow case. Chen et al. $[14,15]$ simulated the separator in its simplest form, i.e. leaving out baffle in two-dimensional model in order to understand its underlying transport phenomena.

In this paper, CFD tool was used to model the flow hydrodynamics concentrating at the inlet and momentum breaker zone. The flow pattern at these regions was examined and interpreted. To the authors' knowledge, there was no literature work that displayed and explained the phenomena so far. After successfully developing a reliable model, it was used to optimise the configuration of perforated baffle that yielded a uniform flow across the cross section of a horizontal separator. Its effect on improving the flow uniformity in a separator was presented. A perforated plate was modelled at $0.3 \mathrm{~m}$ downstream the inlet.

\subsection{NUMERICAL MODELLING}

\subsection{Computational Flow Domain Development}

Figure 2 illustrated the dimensions of the separator with and without baffle which was designed according to industrial design standards [16] and they were modified from the experimental set up in the small-scale LDA experiments by Wilkinson et al.[12]. The thickness of baffle plate was $3.0 \mathrm{~mm}$.

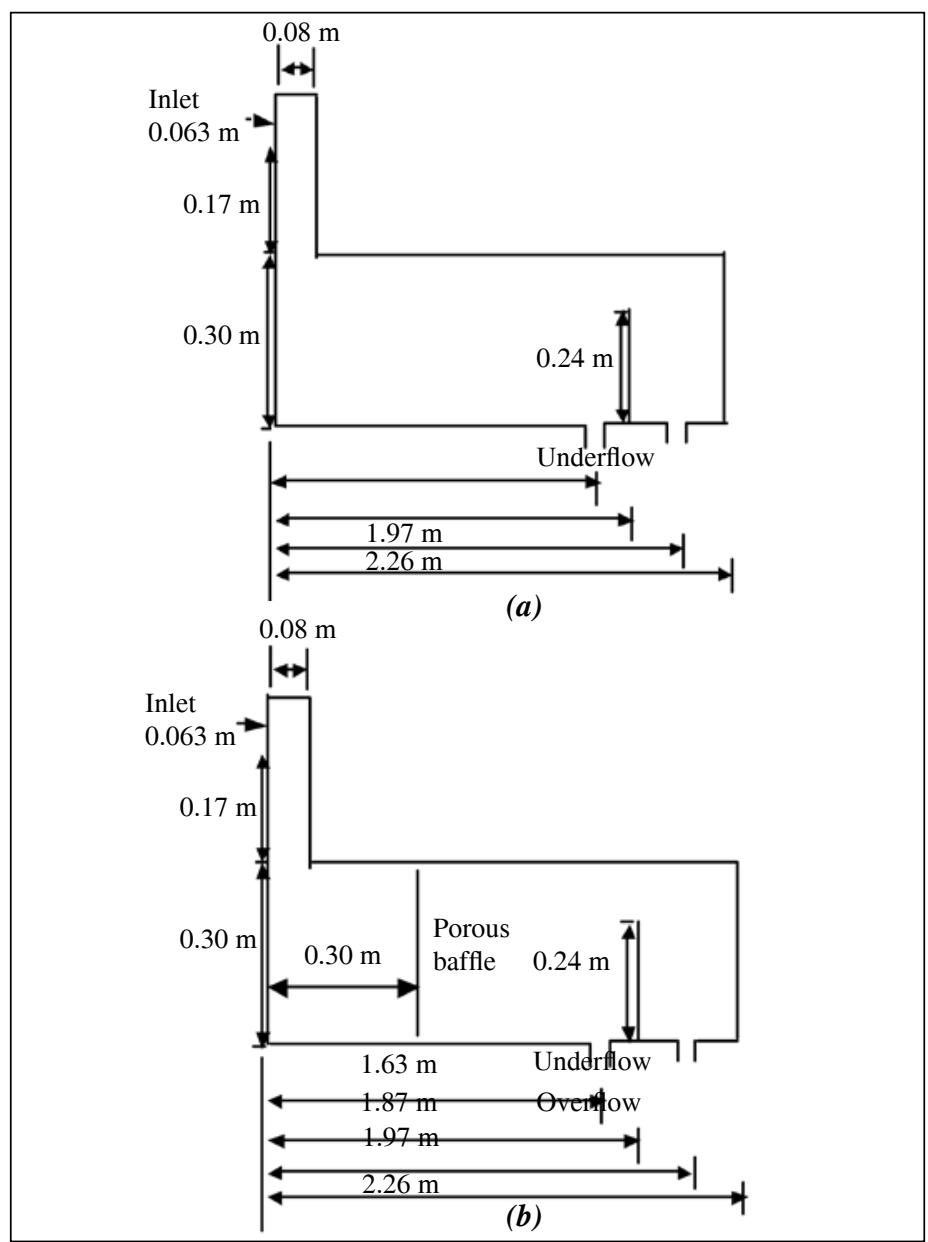

Figure 2: Dimensions of 2D separator

(a) without porous baffle

(b) with porous baffle 
Figure 2(b) showed the insertion of baffle $0.3 \mathrm{~m}$ downstream the inlet. Inlet velocity was in the horizontal direction with the incoming fluid impinging on the wall boundary $0.08 \mathrm{~m}$ downstream the inlet, simulating the momentum breaker region in a real separator.

\subsection{Specifications for simple perforated baffle}

Two different spacing between holes were studied, which were $40 \mathrm{~mm}$ and $69.3 \mathrm{~mm}$ respectively and the diameter of the hole varied from $10.5 \mathrm{~mm}, 15.5 \mathrm{~mm}, 18.5 \mathrm{~mm}$ to $20 \mathrm{~mm}$ for each spacing. Table 1 showed the baffle's configuration simulated in this study. It should be noted that all holes were located along the centre of baffle with a minimum distance of $2 \mathrm{~mm}$ from the top and bottom boundaries of the separator.

Table 1: The configuration of simple perforated baffle

\begin{tabular}{|c|c|c|}
\hline $\begin{array}{c}\text { Diameter/ } \\
\mathbf{m m}\end{array}$ & $\begin{array}{c}\text { Hole spacing/ } \\
\mathbf{m m}\end{array}$ & 2 D Free Area, A/\% \\
\hline 10.5 & 69.3 & 17.5 \\
\hline 15.5 & 69.3 & 26.0 \\
\hline 18.5 & 69.3 & 31.0 \\
\hline 22.0 & 69.3 & 29.0 \\
\hline 10.5 & 40.0 & 28.0 \\
\hline 15.5 & 40.0 & 41.0 \\
\hline 18.5 & 40.0 & 43.0 \\
\hline 22.0 & 40.0 & 51.0 \\
\hline
\end{tabular}

\subsection{Geometry generation}

The problem was first simulated without the perforated baffle by Chen et al. [14].With the inclusion of a perforated baffle, the creation of rectangles was done in accordance to the boundaries of the physical model. Due to the small thickness of the baffle, which was $3.0 \mathrm{~mm}$ and small perforated holes, in the range of $10.5 \mathrm{~mm}$ to $22.0 \mathrm{~m}$ compared to the neighbouring horizontal length of the bulk liquid flow region, in the order of $0.1 \mathrm{~m}$, there were very large numbers of rectangles vertically than in the horizontal direction.

\subsection{Mesh pattern distribution}

Meshing was intensified at region with high gradient in particular towards the thin baffle. Transition from high to low mesh density region should be gradual to avoid numerical instabilities. However, grid density fluctuation was necessary to generate accurate flow predictions in regions of high velocity gradients. The mesh patterns were established such that they concentrated towards regions with steep gradient; recirculation areas, weir, inlets and outlets. A relatively smooth transition in element size from region to region throughout the entire problem domain had to be ensured.

\subsection{Grid generation}

Quadrilateral elements were opted to mesh the geometry forming four nodes at its corners. Mapped meshing was used to mesh the geometry. It gave more accurate results and effectively maintained consistent mesh pattern at the boundaries. Once the mesh was successfully created after investigating the adequacy of meshing intensity, the problem domain cannot be changed during a single analysis [17]. The number of grids ranged between 8000 to 11000 for separators with a baffle fitting. The vast difference in number of elements after the insertion of baffle was due to the requirement of having at least two CFD cells in each hole of baffle on top of small hole size. Figures 3 and 4 display the nodes created for both models without and with baffle. As the hole dimension was small relative to the depth of separator, continuous nodes were observed in the vertical direction in Figure 4 although they were discrete.

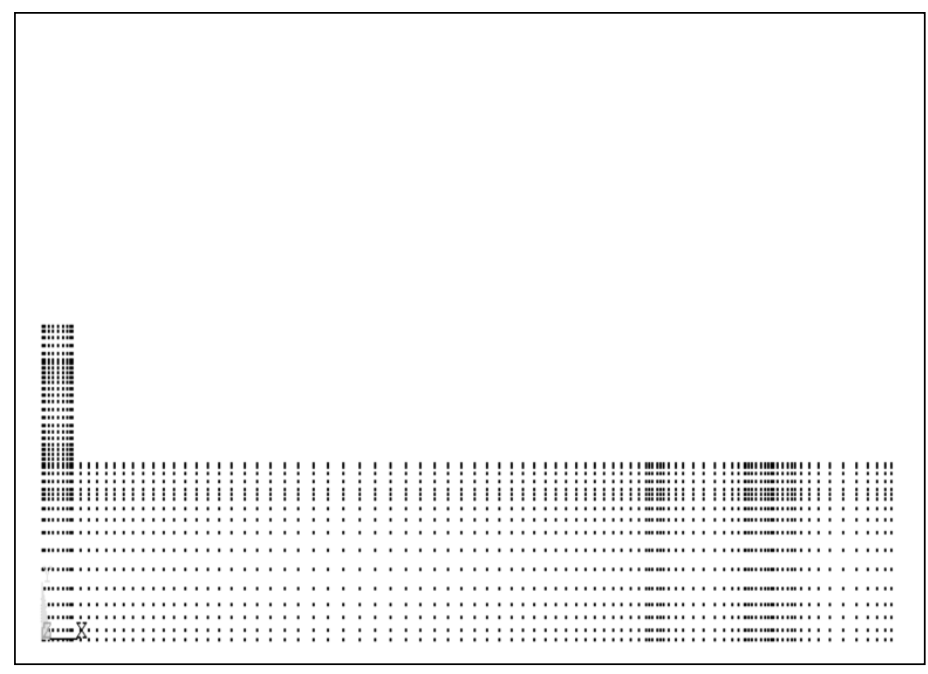

Figure 3: Nodes for model without baffle[14]

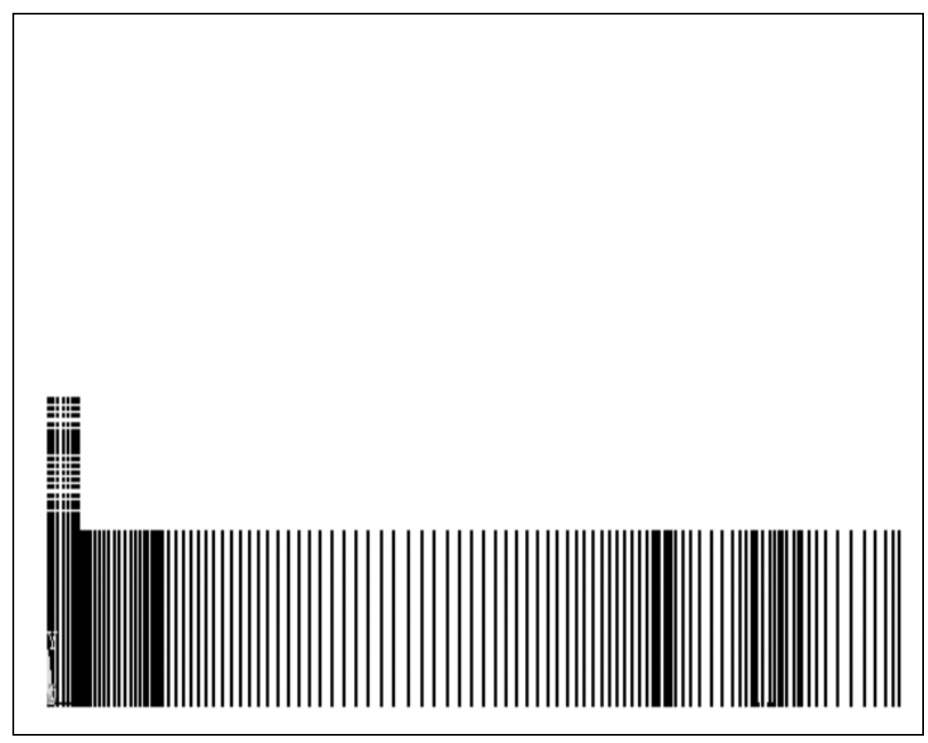

Figure 4: Nodes for model with baffle

As the model with baffle particularly was made up of many rectangular areas with thin surfaces at the baffle, generating a proper mesh came along with problems like faces of adjacent elements did not line up resulting in unspecified boundaries and un-referenced nodes that were not connected into elements. Attention had to be paid on geometry building to ensure that faces of adjacent elements match up and duplicate areas or lines were merged before meshing could be performed. Finer mesh was created and the flow was recomputed until the solution was observed to agree to the order of 0.01 between grid refinements. Baffle was modelled as discrete areas while solid was defined at areas between perforated holes. The computational results from the verification process were discussed in the later section. 


\subsection{Boundary Conditions}

No slip boundary condition was applied to all the fixed walls. Top water surface was modelled as free surface. Inlet flow velocity was $0.08 \mathrm{~m} / \mathrm{s}$ in the $\mathrm{x}$ direction to give an average axial velocity of $0.011 \mathrm{~m} / \mathrm{s}$. This fell within the allowable residence time of 100 to $200 \mathrm{~s}$ and was found iteratively by checking the average velocity for a number of guessed inlet velocities. The outlet relative pressure was set at a constant zero assuming a fully developed isothermal flow.

\subsection{Turbulence modelling}

Reynolds number of the flow based on the depth of water was 4000 characterising it as a turbulent flow. Fluid was assumed to be single phase, water only. Inlet turbulent intensity was set at 0.01 [7]. Turbulent inlet kinetic energy dissipation length was the hydraulic diameter of the separator in this case, which corresponds to the depth of water. $\mathrm{k}-\varepsilon$ model was used as the two-equation models in turbulence modelling.

\subsection{SOLUTION EQUATIONS AND TURBULENCE MODELS}

Standard k- $\varepsilon$ Model [18] is based on eddy viscosity hypothesis for the turbulence. It is employed in this work to simulate the turbulent flow within the separator.

The continuity and momentum equations solved in the computational domains for the k-e model are:

Continuity Equation:

$$
\frac{\partial \mathrm{p}}{\partial \mathrm{t}}+\nabla \cdot(\rho \mathbf{U})=0
$$

Momentum Equation:

$$
\frac{\partial(\mathbf{U})}{\partial t}+\frac{\partial(\rho \mathbf{U} \mathbf{U})}{\partial x j}=\mathrm{B}+\nabla(\sigma-\overline{\rho \mathbf{u u}})
$$

where $\mathbf{U}$ is the fluid velocity vector

$\mathrm{B}$ is the body source term

The momentum, energy, species transport and turbulence equations all have the form of a scalar transport equation which consists of four types of terms: transient, convection, diffusion and source. Bar denotes the time average over one period.

$$
\frac{\partial(\rho \Phi)}{\partial \mathrm{t}}+\nabla \cdot(\rho \mathbf{U} \Phi)=\nabla \cdot(\Gamma \nabla \Phi-\rho \overline{\mathbf{u} \phi)+\mathrm{S}}
$$

where $\Phi$ is the arbitrary scalar

$\Gamma$ is the relevant effective diffusivity for variable $\Phi$

$\mathbf{U}$ and $\Phi$ are primitive variables and

$\mathbf{u}$ and $\phi$ are fluctuating variables

$\mathrm{S}$ is the source term

$$
\frac{\partial \rho k}{\partial t}+\nabla \cdot(\rho \mathbf{U} k)-\nabla \cdot\left[\left(\mu+\frac{\mu_{1}}{\sigma_{k}}\right) \nabla \cdot k\right]=G-\rho \varepsilon
$$

$\frac{\partial \rho \varepsilon}{\partial \mathrm{t}}+\nabla \cdot(\rho \mathbf{U} \varepsilon)-\nabla \cdot\left[\left(\mu+\frac{\mu_{1}}{\sigma_{\varepsilon}}\right) \nabla \varepsilon\right]=\mathrm{C}_{1 \varepsilon} \frac{\varepsilon}{k}\left[\mathrm{C}_{3} \max (G, 0]-\mathrm{C}_{2 \varepsilon} \frac{\varepsilon^{2}}{k}(5)\right.$

where $\mathrm{k}=$ turbulent kinetic energy

$\varepsilon=$ turbulent dissipation energy

$\mathrm{G}=$ production due to body force
Equations (4) and (5) are the respective k and e transport equations for incompressible flow. Turbulent viscosity is computed by equation (6). Input values of turbulent inlet intensity and turbulent inlet dissipation length cause the initialisation of $k$ and $e$.

$$
\begin{aligned}
& \mu_{t}=\text { turbulent viscosity } \\
& \mu_{t}-C_{\mu} \rho \frac{k^{2}}{\varepsilon}
\end{aligned}
$$

The equations comprise five adjustable constants: $C_{\mu}, \sigma_{k}, \sigma_{g}, C_{1 \varepsilon}$, $\mathrm{C}_{2 \varepsilon} \cdot \mathrm{C}_{\mu}$ is a constant derived from dimensional considerations whereas $\sigma_{k}, \sigma_{g}, C_{1 \varepsilon}$, and $C_{2 \varepsilon}$ are the model constants. For the standard k-e model, the values of these constants are: $\mathrm{C}_{\mu}=0.09$, $\sigma_{\mathrm{k}}=1.00, \sigma_{\mathrm{g}}=1.30, \mathrm{C}_{1 \varepsilon}=1.44, \mathrm{C}_{2 \varepsilon}=1.92$.

\subsection{RESULTS AND DISCUSSION 4.1 Effect of number of cells}

Adequacy of grid meshing and effect of turbulent intensity at the inlet were first looked into for a model with perforated baffle. This was to ensure the grid density is adequate, thus creating a reliable model.

Number of cells was increased by intensifying the number of cells from a cell area of $20 \mathrm{~mm} \times 5 \mathrm{~mm}$ to $15 \mathrm{~mm}$ x $5 \mathrm{~mm}$ except at the very thin baffle region which contained three unit cells in the horizontal direction. The solution was found unchanged in its important features looking at the average velocity, the mass inflows and outflows and the recirculation area in the vector plot. Conclusively, mesh refinement had produced little effect. Although denser grids might reveal features of the flow more accurately, numerical truncation errors may arise due to too fine a mesh. Optimum number of cells were kept at 10620.

\subsection{Flow Field in a separator with a perforated baffle}

Two different spacing between holes were studied which were $40 \mathrm{~mm}$ and $69.3 \mathrm{~mm}$ respectively. For each spacing, the hole diameter was varied from $10.5 \mathrm{~mm}, 15.5 \mathrm{~mm}$, and $18.5 \mathrm{~mm}$ to $22 \mathrm{~mm}$. Simulation results of two representative models for each spacing were illustrated and compared. The discussion would emphasize on the flow pattern at the inlet region and bulk liquid zone. The two perforated baffles analysed below had the following configurations

(i) $69.3 \mathrm{~mm}$ hole-spacing, $10.5 \mathrm{~mm}$ hole-diameter and $17.5 \%$ free area's configuration.

(ii) $40 \mathrm{~mm}$ hole-spacing, $10.5 \mathrm{~mm}$ hole-diameter and $29 \%$ free area's configuration.

Figures 5 and 6 show the close-up view of the velocity vector plot from $0.2 \mathrm{~m}$ to $0.5 \mathrm{~m}$ downstream the baffle. There were some flow characteristics which can be observed from the velocity plots close-up near the baffle as shown in Figure 5. Much higher pressure before the hole provided the rate of momentum change of the fluid. As the fluid passed the hole, 


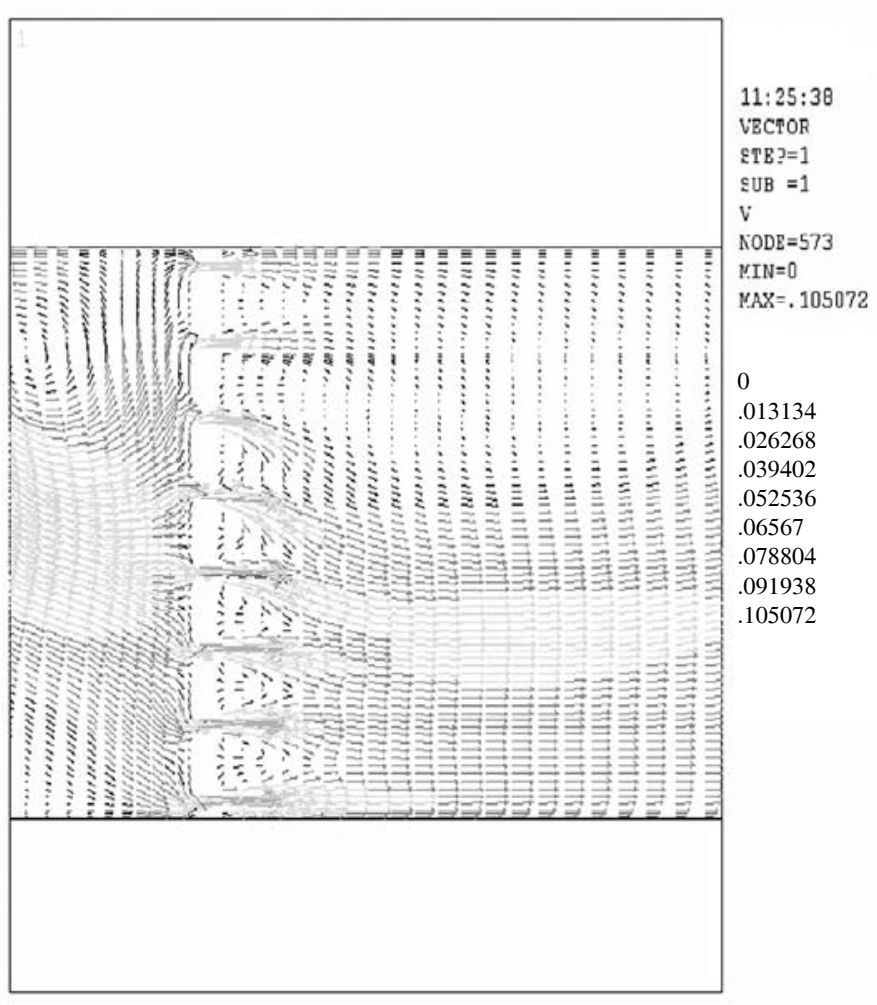

Figure 5: Close-up plot of velocity vector for $10.5 \mathrm{~mm}$ diameter model of $69.3 \mathrm{~mm}$ hole spacing

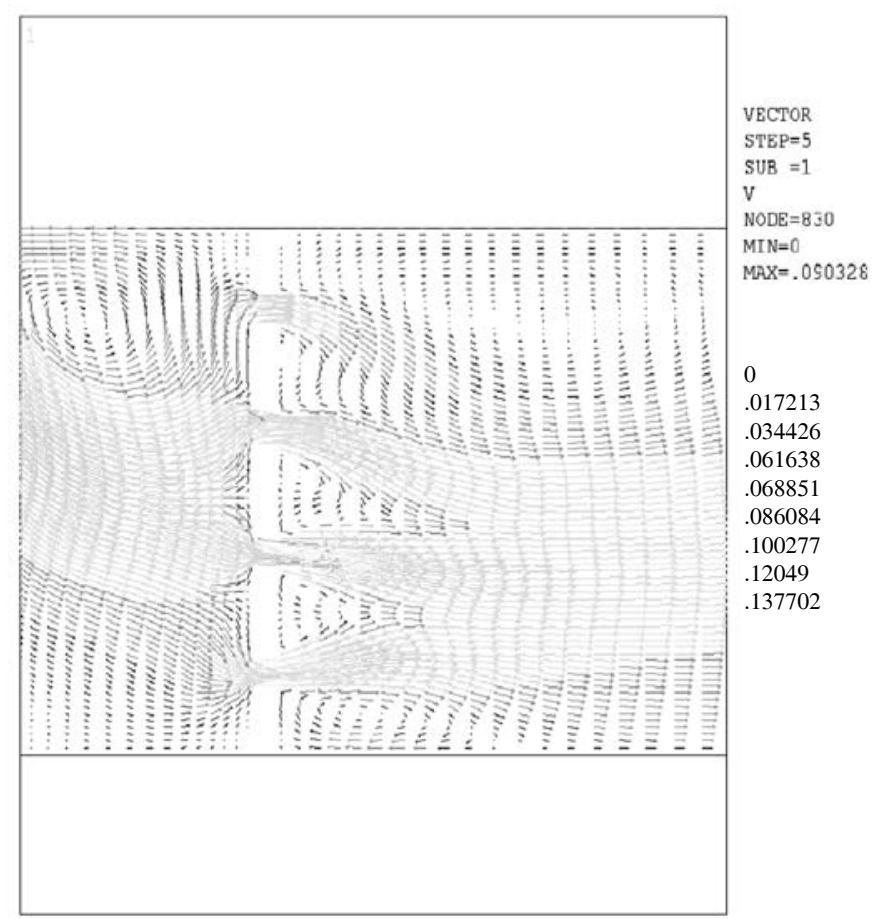

Figure 6: Close-up plot of velocity vector for $10.5 \mathrm{~mm}$ diameter model of $40.0 \mathrm{~mm}$ hole spacing

momentum transfer took place via viscosity, the pressure drop across the hole was expectedly large. Since there was a bounding wall, fluid viscosity effects cannot be neglected and the jet was not a free jet. On the lee side of each hole, which contained the area between two outflows from the holes, reverse flow with low velocity was observed as the fluid at the edge of the jet was being drawn into the jet. The reverse flow in between the jets just after the baffle was due to viscous dissipation. The high speed jet was not able to decelerate efficiently, losing its kinetic energy partially that were dissipated by shear stresses within the fluid. The pressure at the lee side of the hole just next to the baffle was lower than the pressure further downstream, causing reverse flow at the region between the jets just after the baffle. The side fluid of the jet was continually being carried along forming a wider jet downstream. Due to viscous action, redistribution of momentum of different fluid particles just after the baffle would tend to equalise its momentum. The boundary conditions led to the velocity profiles in the region adjacent to the boundaries. The presence of a bottom wall changed the balance of momentum and hence the momentum of a jet which exited a wall at right angles decreased downstream. The jet which was close to the top free surface exhibited more closely the charateristics of a free jet, the velocity was a maximum at the free surface and zero at the edge of the jet.

Comparing both configurations, it was observed that reverse flow persisted further downstream at the region located downstream the uppermost and middle hole for the larger hole spacing as shown in Figure 6 whereas for the smaller hole spacing, the redistribution of momentum tended to equalise the momentum of the jet flow near to the top surface region. Figure 6 showed that the reverse flow tended to persist for a longer distance downstream the baffle. When the hole diameter was increased to $22.0 \mathrm{~mm}$ as shown in Figures 7 and 8, reverse flow was observed

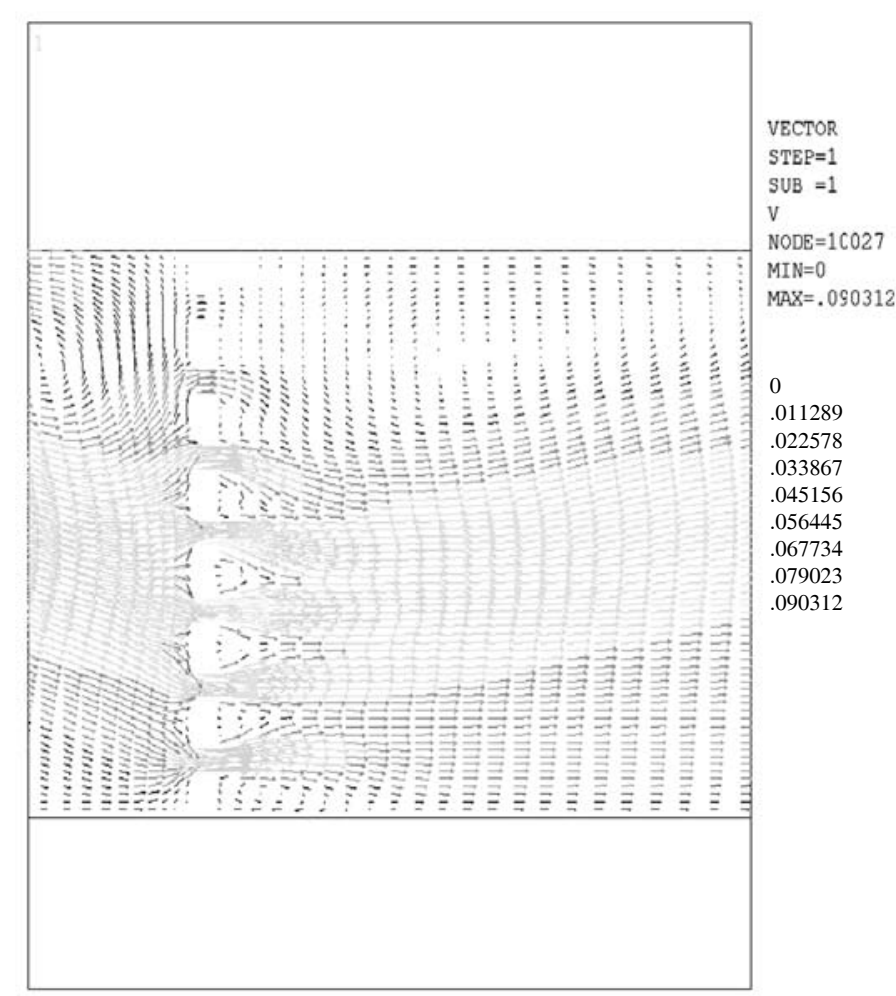

Figure 7: Close-up plot of velocity vector for $22.0 \mathrm{~mm}$ diameter model of $69.3 \mathrm{~mm}$ hole spacing 


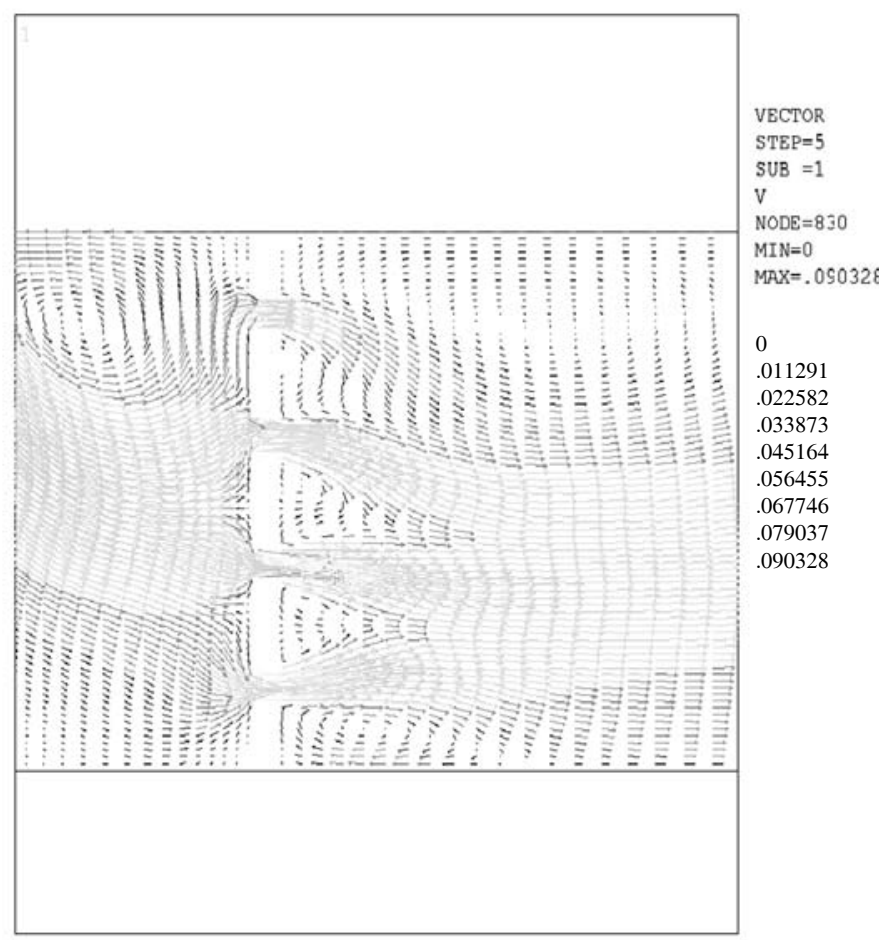

Figure 8: Close-up plot of velocity vector for $22.0 \mathrm{~mm}$ diameter model of $40.0 \mathrm{~mm}$ hole spacing

at the top surface. Examining the hole near to the bottom wall, the jet tended to be pulled onto the wall, reattached with the fluid from other holes. As the flow progressed further downstream the baffle, the velocity profile was similar at different distances downstream. The pressure variations did not extend significantly, hence the flow uniformity was gradually enhanced. As the hole

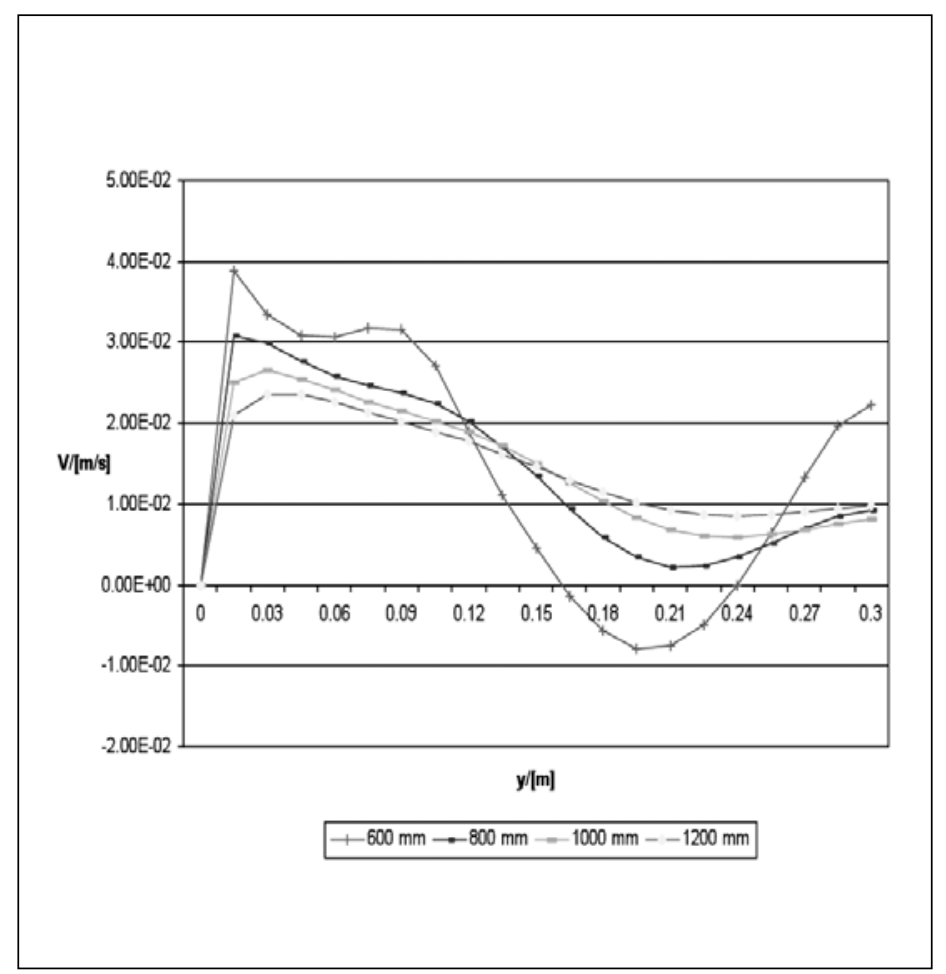

Figure 9: Velocity in [m/s] versus distance from the bottom of separator in [m] for $69.3 \mathrm{~mm}$ spacing spacing decreased from $69.3 \mathrm{~mm}$ to $40.0 \mathrm{~mm}$, Figure 8 showed similar qualitative changes aforementioned for the previous diameter.

Figures 9 and 10 compared the horizontal velocity at four axial positions which were $600 \mathrm{~mm}, 800 \mathrm{~mm}, 1000 \mathrm{~mm}$ and 1200 $\mathrm{mm}$ respectively from the bottom of the separator.

Evidently, reverse flow with maximum attainable absolute value of $0.08 \mathrm{~m} / \mathrm{s}$ was observed as far as $600 \mathrm{~mm}$ downstream the baffle. The velocity profiles show that the flow achieved a maximum value near to the wall and stayed quite uniformly until it reached a $0.13 \mathrm{~m}$ height from the base. It then decreased sharply and picked up again at $0.05 \mathrm{~m}$ below the top surface. Figure 9 showed no recirculation after a distance of $600 \mathrm{~mm}$ downstream the inlet.

\section{Comparison by using standard deviations (SD)}

Velocities were retrieved at 21 equally spaced points along 5 axial positions at $400 \mathrm{~mm}, 600 \mathrm{~mm}, 800 \mathrm{~mm}, 1000 \mathrm{~mm}, 1200$ $\mathrm{mm}$ downstream the inlet. Standard Deviation (SD) was then calculated along these specific axial positions. It indicated the flow uniformity by quantifying the discrepancy of velocity from the average velocity. Its derived data had allowed a more in depth analysis on the performance of every model with a baffle and a comparison with that without baffle.

Table 2 showed the values of SD at $600 \mathrm{~mm}$ downstream the inlet, it was concluded that the more closely spaced hole of $40 \mathrm{~mm}$ spacing gave a comparatively better uniformity. The modelling of hole diameter $10.5 \mathrm{~mm}$ and $28 \%$ free area had yielded the lowest standard deviation, $9.99 \times 10^{-3} \mathrm{~m} / \mathrm{s}$ and $39 \%$ improvement from the model without baffle. This was expected judging at its uniformity of flow in place of the existing recirculation zone of a

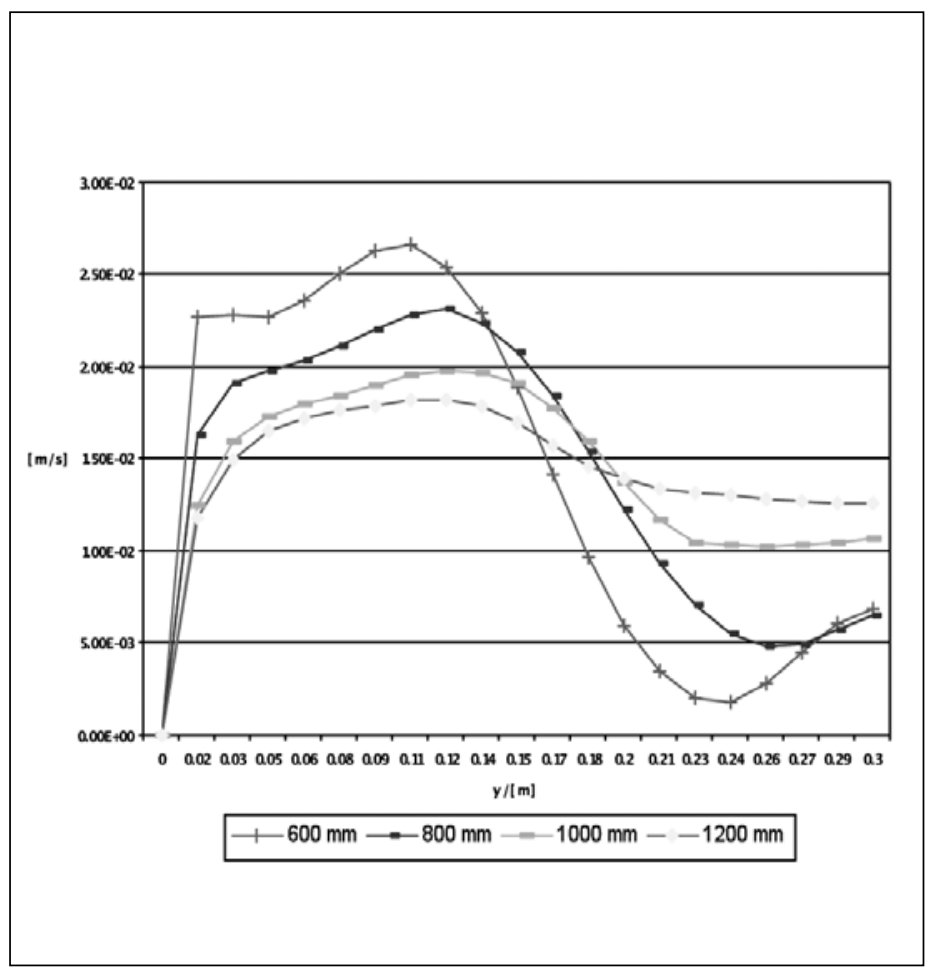

Figure 10: Velocity in [m/s] versus distance from the bottom of separator in [m] for $40.0 \mathrm{~mm}$ spacing 


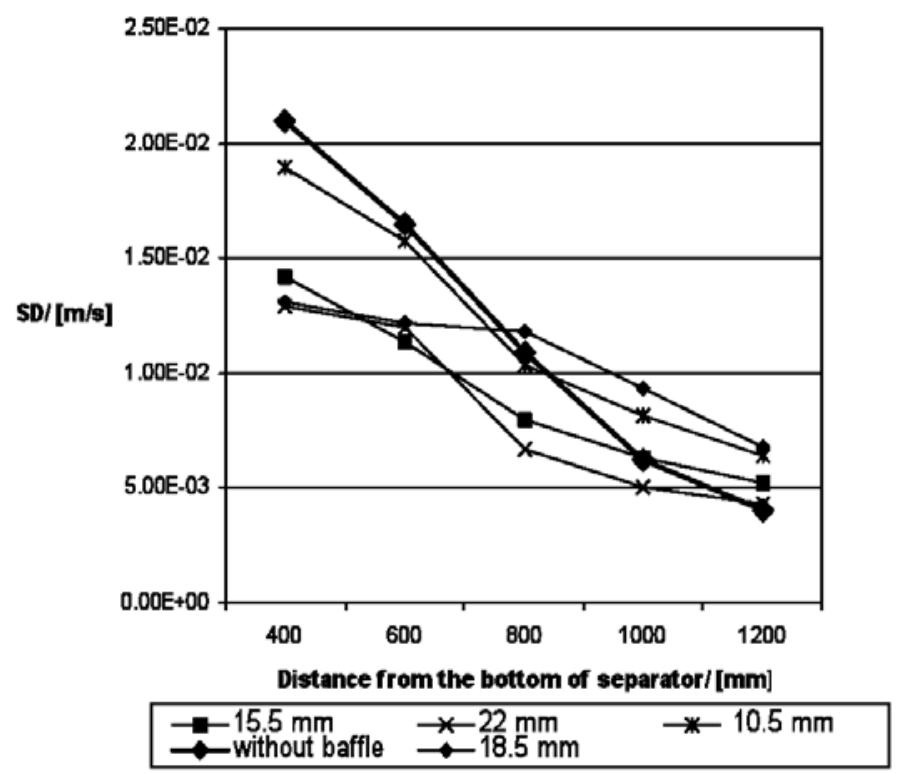

Figure 11: Standard Deviation in [m/s] versus distance from the bottom of the separator in [mm] for hole spacing $69.3 \mathrm{~mm}$

Table 2: A summary of SD values $600 \mathrm{~mm}$ downstream the inlet for $2 D$ Modelling in ANSYS

\begin{tabular}{|c|c|c|c|}
\hline $\begin{array}{c}\mathrm{S}_{1} / \mathrm{mm} \\
40 \mathrm{~mm}\end{array}$ & $\begin{array}{c}\% \\
\text { free area }\end{array}$ & SD $($ total $) / \mathrm{m} / \mathrm{s}$ & $\%$ difference \\
\hline 10.5 & 28 & $9.99 \mathrm{E}-03$ & 39 \\
\hline 15.5 & 41 & $1.14 \mathrm{E}-02$ & 31 \\
\hline 18.5 & 43 & $1.35 \mathrm{E}-02$ & 18 \\
\hline 22 & 51 & $1.15 \mathrm{E}-02$ & 30 \\
\hline No baffle & 100 & $1.65 \mathrm{E}-02$ & \\
\hline $\begin{array}{c}S_{1} / \mathrm{mm} \\
69.3 \mathrm{~mm}\end{array}$ & $\begin{array}{c}\% \\
\text { free area }\end{array}$ & $\mathrm{SD}($ total $) / \mathrm{m} / \mathbf{s}$ & $\%$ difference \\
\hline 10.5 & 17.5 & $1.57 \mathrm{E}-02$ & 5 \\
\hline 15.5 & 26 & $1.13 \mathrm{E}-02$ & 31 \\
\hline 18.5 & 31 & $1.22 \mathrm{E}-02$ & 26 \\
\hline 22 & 29 & $1.20 \mathrm{E}-02$ & 28 \\
\hline No baffle & 100 & $1.65 \mathrm{E}-02$ & \\
\hline
\end{tabular}

model without baffle. However, modelling on larger hole spacing of $69.3 \mathrm{~mm}$ had also managed to improve the uniformity of flow by $31 \%$ for the hole diameter of $15.5 \mathrm{~mm}$ and $26 \%$ free area. Evidently, it showed that the free area of the baffle had a more marked effect on the flow uniformity than the hole diameter.

Figures 11 and 12 were representative of the overall performance of the respective modelling relative to the separator without baffle. It gave further assurance that $40 \mathrm{~mm}$ hole spacing better enhanced the separator performance as indicated by points positioned below the separator except for $18.5 \mathrm{~mm}$ hole diameter.

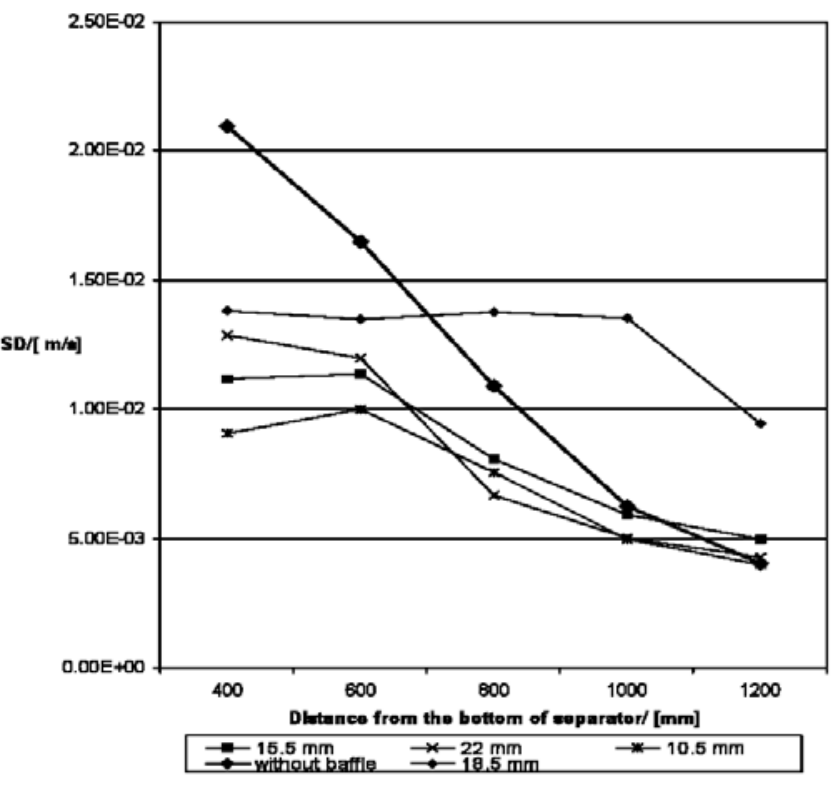

Figure 12: Standard in $[\mathrm{m} / \mathrm{s}]$ versus distance from the bottom of the separator in [mm] for hole spacing $40 \mathrm{~mm}$

Table 3: A comparison of SD between the 2D modeling and literature work

\begin{tabular}{|c|c|c|c|}
\hline $\begin{array}{c}\mathbf{S}_{\mathbf{1}}, \mathbf{6 9 . 3} \\
\mathbf{m m}\end{array}$ & $\begin{array}{c}\text { SD/m/s } \\
\text { (2D Modelling) }\end{array}$ & $\begin{array}{c}\text { SD/ m/s } \\
\text { (Literature [5]) }\end{array}$ & SD/m/s \\
\hline $10.5 \mathrm{~mm}$ & 0.0157 & 0.0147 & 0.0110 \\
\hline
\end{tabular}

Table 3 compared the SD obtained in this work and that done by Hansen, et al. [5] and Wilkinson [13], they were in the same order of values. Therefore, it can be ascertained that this modelling work achieved a fairly good accuracy.

\subsection{CONCLUSION}

The overall 2D CFD numerical predictions had confirmed that perforated baffle enhanced uniformity of flow across the cross sectional area of the separator. Hole spacing of $40 \mathrm{~mm}$ had better improved the flow uniformity than $69.3 \mathrm{~mm}$ spacing with an optimum diameter of $10.5 \mathrm{~mm}$. 2D modelling had justified $28 \%$ as the optimum free area. Standard Deviaton (SD) served as an indicator of flow uniformity along specific axial positions that enables us to compare the performance of the different specifications. Besides that, the SD of CFD modelling were also achievable in the order of the experimental data.

\section{ACKNOWLEDGEMENTS}

The authors expressed gratitude to the Ministry of Science, Environment and Technology of Malaysia for their financial support to make this work possible. 


\section{REFERENCES}

[1] Berger and Anderson, Modern Petroleum, A basic primer of the industry, 2nd Edition, Pennwell, Oklahama, 1981.

[2] K.Arnold, and M. Stewart, Surface Production Operations, vol. 1, Gulf, Texas, 1991.

[3] Taylor, G.I. and Batchelor, G.K., The Effect of Wire Gauze on Small Disturbances in a Uniform Stream, Quarterly Journal of Mechanics and Applied Maths 2, Part 1, pp. 1-29 (1949).

[4] E.P. Spearman, J.A. Sattary and M.J. Reader-Harris, Flow Meas. Instrumentation 7 pp. 181- 199, 1996.

[5] E.W.M. Hansen, H. Heitmann, B. Laksa, A. Ellingsen, O. Ostby, T.B. Morrow and F.T. Dodge, Fluid flow modelling of gravity separators in Proceedings of Conference ' Multiphase production', ed A.P. Burns, pp. 364-380, Elsevier Applied Science, Oxford, 1991.

[6] M.A.A. Rashad, Computational Modelling of Gavity Settlers, M Sc Thesis, UMIST,1995.

[7] M.A.A. Rashad, G.A. Davies and A. Bos, CFD Modelling of Flow Distribution Methods in Primary Separators, The Phoenics Journal of Computational Fluid

[8] D.R. Glynn, J. Creasey and A. Oakes, Simulations of Flow Pattern in Potable Water Reservoirs, The Phoenics Journal of Computational Fluid Dynamics and Its Applications, vol.12, No.1, 1999.

[9] D.R. Glynn and A. Shilton, Reservoir Design Improvement using CFD, The Phoenics Journal of Computational Fluid Dynamics and Its Applications, vol.13, No.1, 2000.

[10] D.Wilkinson and B. Waldie, CFD and Experimental Studies of Fluid and Particle Flow In Horizontal Primary Separators, Trans I Chem E, 72A, (Mac 1994) pp. 189196.
[11] D. Wilkinson and, M.I. Mohamad Nor, CFD Case Study: Single phase flow in a 2 dimensional horizontal primary separator, CFD Industrial Case Studies Seminar, Grantham, September 1996.

[12] D. Wilkinson and M.I. Mohamad Nor, Improving Oil/Water Separation in Primary Separators, World Conference on Particle Technology 3, Brighton, 1998.

[13] D. Wilkinson, B. Waldie, M. I. Mohd Nor and, H.Y. Lee, Baffle Plate CConfigurations to Enhance Separation in Horizontal Primary Separators- Short CCommunication, Chemical Engineering JJournal, vol. 77, Issue 3, (June 2000), pp. 221-226.

[14] G.M. Chen and M.I. Mohamad Nor, "2D CFD Modelling of Hydrodynamics in Horizontal Primary Separator" Regional Symposium of Chemical Engineering, NUS, Singapore, 2000.

[15] G.M. Chen and M.I. Mohamad Nor, "CFD Modelling of Hydrodynamics in Horizontal Primary Separator" Proceedings of National Science Fellowship (NSF) Workshop, Petaling Jaya, Malaysia, 2002.

[16] W.D. Monnery and W.Y. Svreck, Design Two-Phase Separators Within The Right Limits, Chem. Eng. Progress, 89 (10), pp. 53-60 , Oct 1993.

[17] CFX-Build 4, Online Manual, AEA Technology, Dec 1997.

[18] B. E. Launder and D.B. Spalding, Lectures in Mathematical Models of Turbulence, Academic Press Inc., London, 1972.

\section{PROFILES}

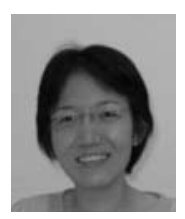

ENG. DR CHEN GOOI MEE is currently a lecturer at the Faculty of Engineering and Technology (FET), Multimedia University. She received her B.Eng.(Hons) in Chemical Engineering from University of Manchester Institute of Science and Technology (UMIST), United Kingdom. She holds a Masters of Engineering in Chemical Engineering from University Malaya. Her research interests include convection in porous medium, boundary layer flow and Computational Fluid Dynamics.

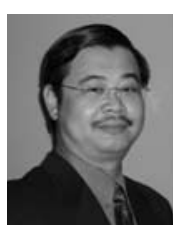

EN. MOHAMAD ISKANDR BIN MOHAMAD NOR is a Senior Lecturer in the Department of Chemical Engineering at University of Malaya (UM), Malaysia. He received his B.Eng. and $\mathrm{MSc}$ in Chemical Engineering from Lakehead University and Queen's University, Canada, respectively. His research interests include applications of Computational Fluid Dynamics in multi-phase mixing and separation, Content Management \& E-Learning systems, Scientific and Educational software developments. 